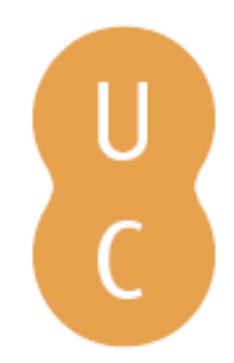

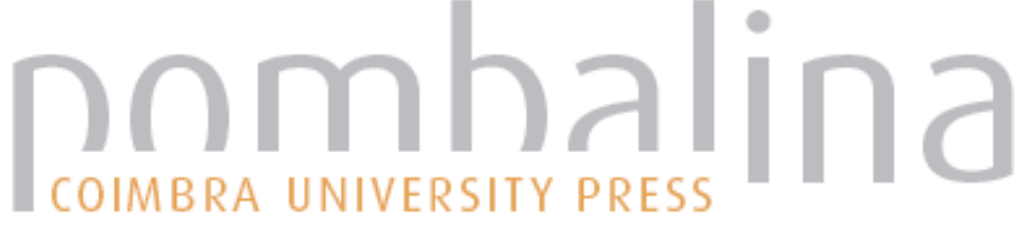

\section{À descoberta do Jornalismo de nova geração}

Autor(es): $\quad$ Figueiredo, António Dias de

Publicado por: Imprensa da Universidade de Coimbra

URL

persistente: URI:http://hdl.handle.net/10316.2/36654

DOI: $\quad$ DOI:http://dx.doi.org/10.14195/978-989-26-0873-0_16

Accessed : $\quad$ 26-Apr-2023 11:24:40

A navegação consulta e descarregamento dos títulos inseridos nas Bibliotecas Digitais UC Digitalis, UC Pombalina e UC Impactum, pressupõem a aceitação plena e sem reservas dos Termos e Condições de Uso destas Bibliotecas Digitais, disponíveis em https://digitalis.uc.pt/pt-pt/termos.

Conforme exposto nos referidos Termos e Condições de Uso, o descarregamento de títulos de acesso restrito requer uma licença válida de autorização devendo o utilizador aceder ao(s) documento(s) a partir de um endereço de IP da instituição detentora da supramencionada licença.

Ao utilizador é apenas permitido o descarregamento para uso pessoal, pelo que o emprego do(s) título(s) descarregado(s) para outro fim, designadamente comercial, carece de autorização do respetivo autor ou editor da obra.

Na medida em que todas as obras da UC Digitalis se encontram protegidas pelo Código do Direito de Autor e Direitos Conexos e demais legislação aplicável, toda a cópia, parcial ou total, deste documento, nos casos em que é legalmente admitida, deverá conter ou fazer-se acompanhar por este aviso.

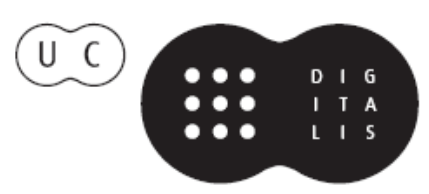


www.uc.pt/ imprensa_uc CONTACTO imprensa@uc.pt VENDAS ONLINE http://livrariadaimprensa.uc.pt JANEIRO 2015
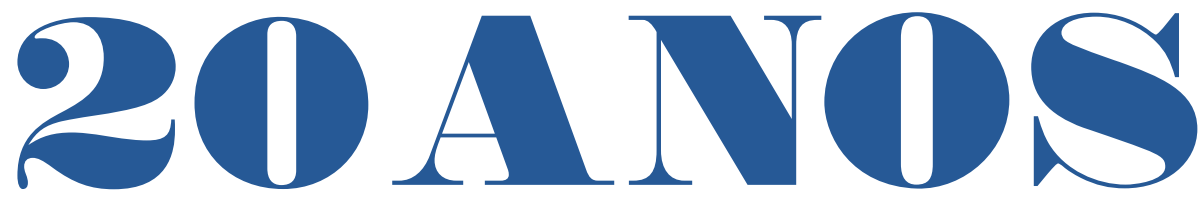

\section{DE JORNALISMO CONTRA A INDIFERENÇA}

TEXTOS DE

Marc Lits, Adriano Duarte Rodrigues, Tito Cardoso e Cunha, José Augusto Mourão, Alberto Pena Rodríguez, Maria Augusta Babo, Daniel Cronu, João Pissarra Esteves, Gilles Gauthier, Heloísa Paulo e Luís Reis Torgal, Alfredo Barroso, António Fidalgo, Nöel Nel, João de Almeida Santos, Juan Luis Cebrián, António Dias Figueiredo, Marina Themudo, Jorge Sampaio, Nelson Traquina, Mário Soares
( livro que agora se apresenta, nasce de dois desígnios fundamentais: por um lado, celebrar duas décadas de ensino do Jornalismo na Universidade de Coimbra e, por outro, partilhar com um público mais alargado um conjunto de reflexões sobre os media, o jornalismo, a comunicação e o espaço público.

Se o ensino superior do Jornalismo em Portugal, relativamente tardio em relação ao resto da Europa, deu os seus primeiros passos no fim dos anos 70 do século passado, ele aparece apenas duas décadas depois na academia coimbrã. Contudo, esta foi, no contexto nacional, a primeira licenciatura em Jornalismo, distinguindo-se, quer em título, quer em objetivos, das licenciaturas então existentes no país. A criação de uma Licenciatura em Jornalismo na Universidade de Coimbra, em 1993-1994, foi, por si, um acontecimento. Com efeito foi necessário que reitor, professores e jornalistas ousassem atualizar a oferta curricular da Faculdade de Letras, oferecendo um curso há muito desejado pela sociedade e pelo mercado, embora desconsiderado por alguns setores da academia. Correndo o risco de omitir alguém, a quem antecipadamente pedimos desculpa, não podemos deixar de recordar os esforços dos jornalistas João Mesquita, João Fonseca, em representação
Todas as gerações, sem dúvida, se julgan para refazer o mundo. A minha sabe, nc que não poderá refazê-lo. A sua tarefa é tc

Consiste em impedir que se desfaça, $p$ unicamente das suas negações A. Camus, Discursos da Suécia (1957)

do Sindicato dos Jornalistas, e de Jorge Castilho, a quem mais tarde se viria associar o nome de Mário Martins, bem como o do então Reitor da Universidade de Coimbra Rui Alarcão, e dos professores João Roque e Luís Reis Torgal. Entre 1993 e 1996, a Licenciatura em Jornalismo funcionou com um Secretariado, que teve um papel executivo e científico nos primeiros tempos do curso na FLUC. Presidido pelo Presidente do Conselho Científico Ludwig Scheidl, este 


\title{
À Descoberta do Jornalismo de Nova Geração*
}

\author{
António Dias de Figueiredo
}

Universidade de Coimbra

O jornalismo é, nos dias de hoje, uma profissão fascinante. Por um lado, vê anunciada com frequência a sua decadência ou extinção. Por outro lado, reinventa-se todos os dias, alarga o seu espaço de intervenção e apresenta-se como uma das profissões do futuro. Este texto parte à descoberta desse futuro, visto pelos olhos de quem se dedica há longos anos à relação entre tecnologias e sociedade. Em particular, é um texto de reflexão sobre as novas visões do jornalismo, os novos públicos, os novos modelos do negócio, as novas retóricas, as novas competências exigidas a quem exerce a profissão e os desafios que se colocam aos novos profissionais.

\section{Novas visões do jornalismo}

Num dos seus trabalhos sobre educação em jornalismo, Donica Mensing (2010) distingue duas visões muito distintas do jornalismo: o jornalismo industrial e o jornalismo comunitário. O jornalismo industrial é aquele que nos vem à mente quando falamos de jornalismo. É o jornalismo produzido no âmbito das indústrias dos media, por jornalistas que recolhem, analisam, concebem e distribuem notícias para um público massificado e anónimo. Embora seja o conceito que prevalece no imaginário dos jovens que acorrem às escolas de jornalismo, e continue a dominar os modelos pedagógicos dessas escolas, a sua sustentabilidade, mesmo no curto prazo, é problemática: a crise do jornalismo dos nossos dias não é uma crise de todo e qualquer jornalismo - é a crise do jornalismo industrial.

Em alternativa ao jornalismo industrial, Mensing (2010) aponta o jornalismo comunitário, também designado por jornalismo social, em rede (Jarvis, 2006; Beckett, 2008) ou cívico. Este jornalismo social assenta na ligação do jornalista à comunidade leitora, com a qual constrói organicamente uma relação em rede. No essencial, corresponde à utopia da Grande Comunidade proposta por Dewey em The Public and Its Problems e à Aldeia Global de Marshall McLuhan.

\footnotetext{
* Conferência proferida na FLUC em 2014.
} 
Curiosamente, a confrontação entre estas duas visões do jornalismo não é nova. Numa célebre polémica sobre o papel do jornalismo em democracia, que opôs nos anos 20 do século passado Walter Lippmann e John Dewey, as visões em confronto eram as mesmas. Lippmann, um reputado jornalista e intelectual norte-americano, exprimia, nos seus livros Public Opinion (Lippmann, 1922) e The Phantom Public (Lippmann, 1925), a convicção de que a democracia era demasiado frágil e o público demasiado ignorante e manipulável para que se pudesse confiar na sua capacidade de formar opiniões e deliberar sobre os grandes problemas coletivos. Nessa perspetiva, a função do jornalista seria dar voz a representações políticas e a competências técnicas que esclarecessem o público sobre como deveria pensar. John Dewey, um prestigiado filósofo e educador, defendia que os leitores eram a essência da democracia e que o papel dos jornalistas era permitir-lhes construir as suas próprias opiniões.

Volvidos mais de noventa anos sobre este debate, sabemos que venceram as conviç̧ões de Lippmann e que o poder dos media na manipulação das mentes e, muitas vezes, na distorção da democracia não deixou de aumentar. No entanto, a evolução da Internet, com a devolução ao cidadão de uma parte significativa do seu poder, está agora a tornar possível a grande comunidade que Dewey sonhava e a aldeia global que MacLuhan antevia. Um exemplo de jornalismo desta nova dimensão é o de Nicholas Kristof, jornalista do New York Times, que averba neste momento mais de 600.000 seguidores no Facebook e escreve muitos dos seus trabalhos em diálogo com eles.

O jornalismo social, de índole profissional, não deve ser confundido com o jornalismo cidadão, trabalho jornalístico amador, que qualquer cidadão pode exercer nos nossos dias. Rosen (2008) caracteriza este último dizendo que é praticado quando aqueles que são conhecidos como a audiência recorrem às ferramentas dos media, hoje ao alcance de qualquer um, para se informarem uns aos outros. O jornalismo cidadão é por vezes olhado com apreensão por alguns profissionais, que o veem como uma ameaça. A resposta é que a diferença entre um jornalista amador e um profissional pode ser tão grande como a diferença entre um atleta amador e um profissional, um pianista amador e um profissional, ou um fotógrafo amador e um profissional. $\mathrm{O}$ talento, construído sobre uma experiência de constante aperfeiçoamento, faz a diferença toda. Tal como o fotógrafo profissional vê coisas que o fotógrafo cidadão não vê, também o jornalista profissional vê coisas que o cidadão comum nunca veria. O talento jorna- 
lístico, assim construído, é, por sua vez, reforçado com modelos, técnicas e ferramentas que o jornalista profissional sabe dominar e que o colocam a uma distância ainda maior do amador.

Embora a temática do jornalismo social seja hoje vasta e impossível de sintetizar em poucas linhas, poderá ser útil resumir aqui alguns dos princípios em que se baseia (Little, 2014):

1. "Há sempre alguém perto da história". A autenticidade é mais importante do que a autoridade. Não podemos ser peritos de tudo, mas podemos encontrar quem seja. Não precisamos de estar em todo o lado, mas podemos encontrar quem esteja.

2. "Histórias sim, conteúdos não". O sucesso não está, como dantes, em divulgar rapidamente as novidades. Está, sim, em enriquecê-las com contexto, narrativa e sentido, numa história que valha a pena ser contada.

3. "Abaixo os boatos e as mistificações". Há que afastar as notícias falsas e destruí-las, se for caso disso. Os jornais estão hoje cheios de notícias em torno de mistificações e construções jornalísticas vazias.

4. "Construção em vez de conversa". Há que trabalhar pacientemente os dados, recorrendo a colaboração e ferramentas, em vez de tentar improvisar uma história sem chama nem autenticidade.

No âmbito do jornalismo de nova geração, começam a surgir novas variantes que prefiguram uma parte do futuro da profissão. Duas delas merecem aqui especial menção: o jornalismo de marca e o jornalismo de dados.

\subsection{Jornalismo de marca}

O jornalismo de marca, jornalismo de imagem ou jornalismo empresarial resulta da convergência entre jornalismo e marketing e tem vindo a acentuar-se muito nos últimos anos à medida que as empresas reconhecem os benefícios de lançar operações de promoção das suas próprias imagens e marcas. Contar histórias é uma das melhores maneiras de comunicar com os clientes, pelo que cada vez mais empresas criam e difundem conteúdos jornalísticos, procurando publicar material credível e sério que lhes permita ganhar a confiança dos clientes.

Os blogs empresariais são hoje a expressão mais corrente do jornalismo de marca e algumas empresas começam mesmo a substituir os seus comunicados à imprensa por notícias que colocam nos seus próprios portais, onde os 
media as vão posteriormente buscar. Outras empresas utilizam as suas plataformas para criarem com os clientes relações de confiança capazes de gerarem intenções de negócio (leads), chegando a oferecer serviços sem qualquer expectativa de retorno, apenas para fortificarem a relação com o cliente e reforçarem a imagem de marca.

Como alguns produtos são pouco conhecidos no mercado e têm dificuldade em atrair os meios de comunicação (por exemplo, a indústria dos sapatos de marca, onde Portugal é um dos maiores exportadores mundiais), algumas empresas assumem nos seus blogs a cobertura noticiosa do respetivo sector, procurando construir notícias de qualidade que possam atrair as atenções da imprensa. Como notícias de qualidade exigem jornalistas de qualidade, algumas empresas fazem hoje melhor jornalismo do que alguns jornais tradicionais, constituindo as suas próprias salas de redação, inspiradas nas dos jornais tradicionais mas com hierarquias e soluções organizacionais ajustadas à realidade do negócio.

Alguns peritos da área distinguem quatro modelos ou formas de intervenção, para o jornalismo de marca (Lyons, n.d.):

1. A sensibilidade à marca (ou brand awareness), para a qual não há intenção explícita de venda.

2. As notícias do sector (ou industry news), que procuram chamar a atenção para o sector no sentido de assegurar que seja citado pelos media.

3. A liderança do sector, ou create and sponsor, que estabelece a empresa como líder do sector e, muitas vezes, como líder de uma forma de ver o negócio.

4. A geração de intenções de compra, ou lead generation, que produz conteúdo jornalístico destinado a gerar intenções de compra.

\subsection{Jornalismo de dados}

O jornalismo de dados combina duas competências básicas do jornalista (Gray, 2012): o sentido da notícia, ou capacidade para distinguir o que vai ser notícia; e o sentido da história, ou capacidade para articular elementos aparentemente irrelevantes numa história que dê prazer ler, ouvir ou ver.

O jornalismo de dados pressupõe o acesso a informação maciça e a ferramentas que a manipulem, permitindo ao jornalista ir para além da mera divulgação da notícia, para analisar tendências e explicar o que é que a notícia significa. Na prática, trata-se de transformar uma massa abstrata de dados numa história que qualquer pessoa compreende e gosta de conhecer. 
Alguns exemplos de atividades de jornalismo de dados permitirão clarificar a sua natureza (Gray, 2012):

1. Programar processos originais de agregação e combinação de informação proveniente de várias fontes, de forma a tornar possível a realização de estudos jornalísticos originais e valiosos.

2. Recorrer a ferramentas de software específicas para explorar ligações entre múltiplos documentos.

3. Dar sentido a grandes números através de tratamentos estatísticos capazes de produzir resultados que interessem ao público.

4. Recorrer a infográficos para contar uma história complexa.

5. Manipular grandes números para descrever como é que que um fenómeno social ou económico afeta o indivíduo comum.

Do ponto de vista instrumental, o jornalismo de dados corresponde ao casamento entre jornalismo e tecnologias da informação. Como não há em Portugal nenhuma universidade que faculte cursos neste domínio, há vários jornalistas, alguns muito experientes, que dedicam parte do seu tempo a formarem-se autonomamente nesse sentido. No que respeita às tecnologias da informação, esta formação pressupõe a familiarização com modelos matemáticos e estatísticos, o domínio de ferramentas informáticas de análise de grandes volumes de dados, o recurso a ferramentas de simulação e visualização de resultados e o desenvolvimento de competências de programação em linguagens ajustadas à criação de plataformas de informação e à análise estatística de grandes volumes de dados.

\section{Novos públicos}

O desafio dos novos públicos coloca-se aos jornalistas pelo menos a quatro níveis. Um primeiro nível é o dos hábitos culturais dos utilizadores da Net: há alguns anos, ligava-se o computador para "ir" à Net; hoje, vive-se num espaço de informação que inclui a Net, sem qualquer descontinuidade entre real e virtual. As implicações desta mudança para o tipo de jornalismo a desenvolver são muitas e ainda estão largamente por descobrir. A existência de cada vez mais blogs e plataformas especializadas de índole comercial a atraírem públicos com culturas muito distintas e exigindo modalidades de jornalismo adaptadas a essas múltiplas culturas são também manifestações do fenómeno.

Outro nível de desafio é o das redes sociais. Com a deslocação recente da atividade comercial para as redes sociais, começaram a surgir valiosas opor- 
tunidades para os jornalistas. Em boa verdade, à luz do jornalismo de marca, que acima mencionei, os jornalistas, sobretudo os que adquiriram aptidões adicionais para o marketing, passaram a contar-se entre os profissionais mais credenciados para gerirem a presença de uma empresa ou marca nas redes sociais.

Um terceiro nível de desafio é o dos dispositivos móveis, tablets e smartphones, cuja popularidade está a provocar acentuadas alterações culturais e a abrir oportunidades para novos produtos jornalísticos.

Finalmente, um quarto nível é o da crescente bidirecionalidade e sentido comunitário do relacionamento entre jornalista e audiência, que também está a provocar alterações no potencial do jornalismo e nas modalidades de jornalismo praticáveis.

\section{Novos Modelos de Negócio}

A problemática dos novos modelos de negócio pode ser analisada segundo duas perspectivas: a dos jornalistas individuais e a das empresas de media.

\subsection{Modelos de negócio dos jornalistas}

Do ponto de vista do jornalista existem hoje dois modelos distintos: os modelos de remuneração e os modelos de reputação. Nos modelos de remuneração, recebem-se honorários para prestar serviços, segundo duas modalidades: salário fixo e freelancing. O modelo de salário fixo está em rápida decadência, ao contrário do modelo de freelancing, que, depois de se ter tornado popular entre engenheiros, arquitetos e advogados, que preferem trabalhar por conta própria, está agora a generalizar-se também aos jornalistas.

Os modelos de reputação são cada vez mais populares. No essencial, baseiam-se em um profissional recorrer aos media para adquirir reputação. $\mathrm{Na}$ maior parte dos casos, não recebe qualquer honorário por essa exposição pública. Uma vez conseguida a reputação, que terá de ser mantida, o profissional passa a prestar, para outros clientes, serviços remunerados, que serão tanto mais bem pagos quanto maior for a sua reputação. Os comentadores que vemos nas nossas televisões e os autores de blogs hoje muito populares usam essas atividades precisamente para adquirirem e manterem reputação.

Provavelmente, a profissão que há mais tempo explora o modelo de reputação é a docência universitária. Como sabemos, um docente universitário não é contratado por ser um bom pedagogo, mas sim pela reputação que tem como autor de publicações científicas. Possuindo boa reputação como cientista, não só tem muito maior facilidade em ver financiados os seus pro- 
jetos, como contribui para a reputação global da universidade, que assim angaria melhores financiamentos e atrai melhores alunos. Gera-se assim o aparente absurdo de um docente ser pago para dar aulas mas ser contratado por ter boa reputação como cientista, mesmo que as suas aulas sejam medíocres. Os engenheiros de software que produzem código de acesso aberto são outro exemplo corrente do modelo de reputação. O trabalho que realizam no âmbito dos projetos de acesso aberto é gratuito, mas a competência e reputação que adquirem nesses projetos permitem-lhes cobrar posteriormente, com elevados honorários, os serviços remunerados que prestam a outros clientes.

Uma variedade adicional de remuneração, que apenas funciona nos mercados que valorizam o trabalho intelectual, é a doação. Quando um consumidor retira prazer ou benefício de um trabalho colocado online, seja ele escrito ou em multimédia, poderá remunerar o seu autor enviando-lhe uma doação. O blog BrainPickings.org, dedicado a temas de cultura e literatura, mantido pela escritora, blogger e crítica búlgara Maria Popova, que vive em Nova Yorque, é exemplo de uma iniciativa de grande sucesso baseada na reputação que a autora granjeou através do blog, ao mesmo tempo que recorria à sua divulgação inteligente e sistemática no Twitter. Graças a essa reputação, Maria Popova é hoje consultora de várias instituições de referência, embora mantenha o blog como tarefa principal, para a qual convida os seus leitores a contribuírem com doações.

\section{Modelos de negócio das empresas de media}

Antes da emergência da Internet, as empresas de jornalismo controlavam três componentes, que hoje se encontram desagregadas: o canal de distribuição, o produto e o modelo de rendimento. O canal de distribuição é hoje a Internet, com custos praticamente nulos. A Internet como canal tem, entretanto, vindo a evoluir. Inicialmente, centrava-se nos portais online; depois, fez emergir os motores de pesquisa; mais tarde, deu origem às redes sociais; e presentemente contribuiu para a generalização do recurso a dispositivos móveis.

Quanto ao produto, tem vindo a tornar-se cada vez mais complexo. Do texto tradicional, ilustrado ou não, passou-se em pouco tempo para produtos multimédia sofisticados e para a participação ativa das audiências em redes sociais. Os modelos de rendimento têm vindo a evoluir ao mesmo ritmo. Dos modelos de assinatura e anúncios, que já caracterizavam os jornais tradicionais, evoluiu-se em pouco tempo para modelos de contagem e para sis- 
temas de avaliação baseados na atividade em redes sociais e em dispositivos móveis. Bastará referir alguns modelos de contagem associados ao recurso a anúncios para se compreender como a realidade do presente é tão distinta da do passado: CPU, custo por utilizador (proporcional ao número de utilizadores que visitam um anúncio); CPC, custo por click; CPM, custo por milhar; $\mathrm{CPV}$, custo por visualização; $\mathrm{CPA}$, custo por aquisição.

Em resumo, os modelos de rendimento estão ainda em grande transformação. O New York Times tem vários modelos interessantes, incluindo o clássico, de assinaturas e anúncios, mas mantém-se insatisfeito quanto à sua capacidade de penetração no mercado. O Público tem um modelo de assinatura online aceitável. O mesmo acontece, para os jornais regionais, com As Beiras. O Expresso tem um preço de assinatura online razoável, mas não disponibiliza a totalidade dos suplementos, transformando a assinatura online numa assinatura de segunda categoria. De um modo geral, no entanto, nota-se que as empresas de media tradicionais têm dificuldade em compreender o comportamento dos mercados online, onde os custos marginais são nulos ${ }^{1}$ as leis das economias lineares do passado dão hoje lugar a leis mais complexas, como as "leis de escala" ou "leis de potência" (power laws). A título de exemplo, um jornal online, pago, que custasse cinco vezes menos para atingir um público dez vezes maior, que nunca seria público se o preço fosse mais elevado, ficaria a ganhar o dobro.

\section{Novas retóricas}

As retóricas dos media também estão a mudar. Por um lado, os públicos e os hábitos culturais mudaram. Por outro, as tecnologias transformaram-se, com as retóricas da Web a distanciarem-se cada vez mais das do papel. Além disso, expandiram-se imensamente as possibilidades de miscigenação entre práticas - o discurso da escrita usa hoje retóricas do cinema, o discurso multimédia inspira-se no vídeo, mas também na publicidade e nos jogos, e as possibilidades de combinação entre retóricas tornaram-se infinitas. Não menos desprezável é o potencial hipertextual dos novos suportes, que permite integrar num mesmo "documento" múltiplos discursos de texto, áudio e vídeo, eventualmente localizados em plataformas distintas. São também possíveis novos tipos de jornalismo, assentes em novos tipos de discurso, como o "jornalismo explicativo", que hoje conhece particular recetividade (Doctor, 2014).

${ }^{1}$ Visto que o custo de produção de uma única unidade é igual ao custo de produção de milhares ou milhões de unidades. 


\section{Novas competências dos jornalistas}

Para confrontar os desafios acima aflorados, os jornalistas necessitam de desenvolver novas competências - quer técnicas, quer não técnicas.

\subsection{Competências técnicas}

Entre as competências técnicas, cabe mencionar algumas mais relevantes:

1. Conhecimento especializado na área em que escreve. Tendo em conta que hoje há pouco espaço para generalistas, cada jornalista terá vantagem em desenvolver uma imagem profissional própria, especializando-se num conjunto restrito de domínios que lhe permitam criar o seu próprio nicho. A especialização poderá ser cultivada a níveis vários: de disciplinas ou áreas de estudo, de competências (por exemplo, linguísticas) ou de familiarização com contextos geográficos ou culturais específicos.

2. Competências em análise de dados e estatística, para destrinçar o que é relevante do que não o é e para agregar o que só faz sentido se for agregado. A capacidade para encontrar significado em agregados complexos de dados é hoje uma importante competência de um jornalista.

3. Compreensão de métricas e audiências. Perceber como é que as audiências estão a reagir, desenvolver sensibilidade para o que vai ser popular, reconhecer tendências e antecipar a recetividade a conteúdos jornalísticos.

4. Programação. Possuir literacia de programação para, pelo menos, saber o que pedir a quem constrói as plataformas (saber utilizar, por exemplo, JavaScript, CSS, HTML, ou Markdown). Há hoje jornalistas que, nos aspetos relacionados com a escrita de código para a Web, discutem de igual para igual com os profissionais de informática.

5. Capacidade para contar histórias. A capacidade para contar histórias com interesse jornalístico é hoje significativamente distinta da do passado porque depende da verificação e agregação de fluxos de informação provenientes de fontes muito diversas.

6. Gestão de projeto. Os múltiplos projetos editoriais dos nossos dias têm de ser concebidos, criados e geridos, exigindo boas competências de organização e gestão por parte dos jornalistas envolvidos. Esta necessidade relaciona-se também com a diminuição dos recursos humanos na sala de redação.

\subsection{Competências não-técnicas}

Entre as competências não-técnicas (soft skills), cabe destacar as seguintes:

1. Atitude. Uma característica importante do bom jornalista é confiar na sua capacidade para exercer um efeito transformador positivo sobre o seu 
público, combinando sensibilidade, confiança, imaginação e competência, um conjunto de atributos que exige longo e paciente cultivo.

2. Vivência em rede. Um jornalista tem sempre múltiplas redes - de fontes, contactos, colegas, potenciais parceiros, leitores (com quem pode ter vantagem em criar comunidade). Um jornalista que não tem redes sólidas não é um jornalista.

3. Personalidade. Presença pessoal, acessibilidade, fiabilidade, integridade, valores, empatia, que se tornem visíveis no que é escrito ou produzido e são a base de uma sólida reputação. Dantes, a personalidade, entendida neste sentido, era um atributo que só se esperava das grandes figuras do jornalismo. Hoje, em qualquer forma de jornalismo, a solidez da personalidade é essencial porque a imagem pessoal do jornalista é pública e rapidamente comentada e propagada. Qualquer atropelo aos valores da profissão é imediatamente tornado público, com implicações potencialmente desastrosas para a reputação do jornalista.

\section{Desafios aos jovens profissionais}

Para fazer frente aos desafios que hoje se colocam aos jovens profissionais, costumo recomendar os cinco princípios seguintes, que se me afiguram particularmente apropriados para os jornalistas da nova geração.

\subsection{Princípio da incerteza}

Uma característica cada vez mais marcante do mundo de hoje é a incerteza. Quem não cultivar a capacidade para viver em incerteza terá grande dificuldade em sobreviver profissionalmente. E quem se deixar aprisionar por certezas acidentais, convicto de que vão durar, expõe-se a grandes desilusões. Por isso, todo o jovem profissional deverá abandonar a sua zona de conforto e tentar construir a excelência no seio da incerteza. Foi isso que os navegadores portugueses fizeram há quinhentos anos. É isso que os profissionais de sucesso fazem hoje todos os dias. Há muito pouco que se possa descobrir nos territórios que já conhecemos. Por isso, todo o jovem profissional deve explorar os limites do que sabe e abrir os braços a descobertas inesperadas.

\subsection{Princípio da diferenciação}

Há dois tipos de uniformidade nos sistemas sociais onde nos movimentamos: a boa uniformidade e a má uniformidade. A boa uniformidade é a que nos permite conviver e trabalhar em harmonia com os que nos rodeiam. Não só é boa como é indispensável. A má uniformidade é a rotina e a sujeição 
obediente a princípios que nos são impostos e que contrariam os nossos valores. Para combater a má uniformidade é preciso ter a coragem de ser diferente. As nossas mãos são dos mecanismos mais flexíveis e poderosos que existem, precisamente porque são diferentes e se complementam e ajudam mutuamente. Infelizmente, a uniformidade das nossas escolas tem-nos feito iguais uns aos outros. Uma das explicações para os baixos salários das populações jovens é que os jovens profissionais não tendem a cuidar de construir a sua diferença, desde os bancos da escola, e a afirmá-la claramente no mercado de trabalho. Quando um recrutador olha para o mercado e vê candidatos todos iguais, sabe que poderá pagar pouco porque, se um deles recusar, haverá sempre outro, outro e outro, mais ou menos igual, que aceitará o salário reduzido que ele oferece. Todo o jovem profissional - em boa verdade, todo o profissional - deve cultivar em permanência o seu valor, que o torne diferente e único. E deverá cultivar esse valor de forma a que se associe ao valor dos outros. As soluções para os problemas complexos dos nossos dias só se conseguem quando pessoas diferentes colaboram. Para que a inteligência coletiva floresça, a diversidade é essencial.

\subsection{Princípio da dificuldade}

Muitos profissionais reagem negativamente às tarefas ou cargos difíceis. A verdade é que as tarefas fáceis não contêm desafios. E, na ausência de desafios, tendemos a tornar-nos passivos, acomodados e uniformes. O percurso de menor resistência, ou de menor dificuldade, raramente conduz ao sucesso. Por outro lado, a dificuldade está ligada à frustração. Os bons profissionais têm uma resistência quase infinita à frustração. E quando se sentem frustrados, o que acontece com frequência na vida profissional, não ignoram a frustração, nem se debatem irracionalmente contra ela. Param para a compreender e, com paciência renovada, superam-na. A verdade é que muitas das grandes vitórias se escondem do lado de lá de uma barreira aparentemente impenetrável de frustrações.

\subsection{Princípio da colaboração sustentável}

O mundo onde hoje trabalhamos é feito de colaboração, equipas e comunidades. Se quisermos que as nossas colaborações sejam sustentáveis, temos de nos preocupar em permanência, não apenas com o interesse que a colaboração ou parceria terá para nós, mas também com o interesse que as outras partes irão retirar da colaboração. Caso contrário, as outras partes desinteressam-se, a colaboração colapsa, e todas as partes perdem. Assim, sempre 
que um profissional queira assegurar uma colaboração duradoura, deverá interrogar-se sobre o interesse que a outra parte terá na colaboração. Esta sugestão poderá parecer ingénua no mundo de hoje, mas alinha com um dos mais célebres princípios da ética - o princípio Kantiano do imperativo categórico. Todos nós conhecemos o provérbio que diz: "não faças aos outros o que não queres que te façam a ti". O imperativo categórico diz o mesmo, mas pela positiva: "faz aos outros o que queres que te façam a ti".

\subsection{Princípio da paixão}

O bom profissional procura apaixonar-se pelo que faz e fazer o que o apaixona, evitando a todo o custo agir como o funcionário que só faz o que lhe mandam, quando lhe mandam. O bom profissional abraça a iniciativa, autonomia, entusiasmo, sentido de realização e melhoria contínua como uma obsessão saudável. Se o fizer, a sua profissão, neste mundo cheio de oportunidades, será um garantido sucesso.

\section{Conclusões}

Neste artigo, procurei abordar algumas das características do jornalismo de nova geração, nomeadamente novas visões sobre a sua natureza, públicos, modelos de negócio, retóricas e competências que exige aos seus profissionais. O caráter mutável do jornalismo dos nossos dias faz dele, pelas oportunidades de inesgotável renovação que oferece aos seus profissionais, uma das profissões mais fascinantes da atualidade.

\section{Referências}

Beckett, C. (2008). Supermedia: Saving Journalism So It Can Save the World. WileyBlackwell.

Dewey, J. (1927). The Public and its Problems. New York: Holt.

Doctor, K. (2014). The newsonomics of how and why. Nieman Journalism Lab. Consultado em 30 de julho de 2014: http://www.niemanlab.org/2014/o7/ the-newsonomics-of-how-and-why/

Gray, J., Chambers, L. e Bounegru, L. (2012). The Data Journalism Handbook: How Journalists Can Use Data to Improve the News. O'Reilly Media

Jarvis, J. (2006). Networked journalism. BuzzMachine. Consultado em 30 de julho de 2014: http://www.buzzmachine.com/2006/07/05/networked-journalism/

Lippmann, W. (1922). Public Opinion. New York : Free Press.

Lippmann, W. (1925). The Phantom Public. New York: Harcourt. 
Little, M. (2014). Ten Principles That Power Social Journalism. Storyful blog. Consultado em 30 de julho de 2014: http://blog.storyful.com/2014/03/12/ten-principles-that-power-social-journalism/\#.U9pZl4BdU-U

Lyons, D. (n.d.). The CMO's Guide to Brand Journalism. Vol. 1. Hubspot.com.

http://www.hubspot.com/cmos-guide-to-brand-journalism/four-models

Mensing, D. (2010). Rethinking (Again) the Future of Journalism Education. Journalism Studies, 11(4), 511-523.

Rosen, J. (2008). A Most Useful Definition of Citizen Journalism. Press Think. Consultado em 30 de julho de 2014: http:/|archive.pressthink.org/2008/ o7/14/a_most_useful_d_p.html 